\title{
Treatment Strategies for Recurrent Clostridium difficile Infection
}

\author{
Christine Leong and Sheryl Zelenitsky
}

\begin{abstract}
Background: Recurrent Clostridium difficile infection represents a major clinical challenge. Treatment is often based on empiric selection from relatively few options supported by limited clinical evidence.

Objective: To review and evaluate the literature on therapeutic alternatives for recurrent $C$. difficile infection.

Data Sources: The MEDLINE, PubMed, Embase, and Cochrane databases were searched from inception to 2013 for published evidence in English on the treatment of recurrent $C$. difficile infection. The search terms were "Clostridium difficile", "recurrent" or "relapse", and "treatment".
\end{abstract}

Study Selection and Data Extraction: Studies of any design were eligible for inclusion. Two reviewers assessed abstracts, full articles, and reference lists from retrieved articles and clinical practice guidelines to identify relevant literature.

Data Synthesis: The evidence to guide treatment of recurrent $C$. difficile infection is limited, with 24 studies meeting the inclusion criteria for this review. A repeat course of oral metronidazole or vancomycin is recommended for treatment of mild to moderate first recurrences and has not been found to influence the likelihood of subsequent recurrence. Oral vancomycin may be preferred for more severe infections; however, the severity score warrants further study and validation. For the treatment of second and subsequent recurrences, tapered or pulsed vancomycin regimens have been recommended in practice guidelines, despite very limited clinical evidence. Similarly, the potential benefits of longer treatment courses of oral vancomycin for second and subsequent recurrences warrant investigation. The potential role, including costs and benefits, of new agents such as fidaxomicin in the treatment of recurrent $C$. difficile infection remains to be determined. Although there is insufficient evidence to recommend probiotics as an adjunct to conventional treatment for recurrent infection, there may be benefit in terms of prevention.

Conclusions: This literature review identified significant limitations in currently recommended interventions for the treatment of recurrent $C$. difficile infection. It has also provided insight into the available evidence for determining the appropriateness of therapy for patients with recurrent infection.

Keywords: recurrent Clostridium difficile infection, relapse, vancomycin, metronidazole, fidaxomicin, literature review

Can J Hosp Pharm. 2013;66(6):361-8

\section{RÉSUMÉ}

Contexte : Les récidives d'infection à Clostridium difficile constituent un défi clinique majeur. Le traitement est souvent basé sur un choix empirique parmi relativement peu d'options étayées par des données cliniques probantes limitées.

Objectif : Examiner et évaluer les traitements de rechange des récidives d'infection à $C$. difficile dans la littérature.

Sources de données : Les bases de données MEDLINE, PubMed, Embase et Cochrane ont été interrogées depuis leur création jusqu’en 2013 pour trouver des données probantes publiées en anglais sur le traitement des récidives d'infection à $C$. difficile. Les mots clés utilisés étaient "Clostridium difficile», " récidive " ou " rechute » et « traitement ".

Sélection des études et extraction des données : Toutes les études, peu importe la méthodologie, étaient admissibles. Deux examinateurs ont évalué les résumés, les articles complets, et les listes de références des articles et des guides de pratique clinique recensés afin de repérer la littérature pertinente.

Synthèse des résultats : Les données guidant le traitement des récidives d'infection à $C$. difficile se limitent à vingt-quatre études qui ont satisfait aux critères d'admissibilité à cet examen documentaire. Une reprise du traitement par le métronidazole ou la vancomycine par voie orale est recommandée pour les premières récidives légères ou modérées et s'est révélée sans incidence sur le risque d'autres récidives. La vancomycine orale pourrait être mieux indiquée dans les cas d'infection plus grave; en revanche, le score de gravité mérite de faire l'objet d'études plus poussées et d'être validé. Pour le traitement des deuxièmes récidives et des récidives subséquentes, des traitements dégressifs ou intermittents par la vancomycine ont été recommandés dans les guides de pratique, malgré des données cliniques probantes très limitées. De même, les atouts potentiels des traitements de plus longue durée par la vancomycine orale dans les cas de deuxièmes récidives et de récidives subséquentes doivent être davantage étudiés. Le rôle potentiel, y compris les coûts et les bénéfices, des nouveaux agents comme la fidaxomicine dans le traitement des récidives d'infection à $C$. difficile reste à déterminer. Malgré les données probantes insuffisantes pour recommander les probiotiques comme adjuvant au traitement classique des récidives d'infection, ces agents pourraient exercer des effets préventifs favorables.

Conclusion : Cet examen de la littérature a relevé des limites considérables dans les interventions actuellement recommandées pour le traitement des récidives d'infection à $C$. difficile. Il a aussi jeté un nouvel éclairage sur les données disponibles permettant de déterminer la pertinence du traitement dans les cas de récidive de l'infection.

Mots clés : récidive d'infection à Clostridium difficile, rechute, vancomycine, métronidazole, fidaxomicine, examen de la littérature

[Traduction par l'éditeur] 


\section{INTRODUCTION}

$\mathrm{R}$ ecurrent Clostridium difficile infection, defined as symptoms and a positive toxin result within 8 weeks after the end of therapy for an initial episode, represents a major clinical challenge..$^{1-9}$ A first recurrence occurs in $20 \%$ to $30 \%$ of patients treated for an initial episode, and subsequent (second or later) recurrences are observed in $40 \%$ to $60 \%$ of those cases. ${ }^{1-3,5,6} C$. difficile infection, especially recurrent disease, is associated with significant patient morbidity and can lead to serious and even life-threatening complications such as pseudomembranous colitis, bowel perforation, and sepsis. ${ }^{1-3,5}$ Reports indicate that the incidence of $C$. difficile infection, including recurrent infection, is on the rise., ${ }^{5,-9}$

Recurrent episodes may be due to re-infection from persistent spores or new infection with a different strain of $C$. difficile. ${ }^{1-3,5,9}$ The risk of re-infection increases with continued use of antimicrobials, advanced age, history of recurrence, and deficiency in the immune response to $C$. difficile toxins. ${ }^{1-3,7,8}$ Recurrence may also be influenced by bacterial strain; for example, the toxin hyper-producing BI/NAP1/027 (NAP1) strain emerged during outbreaks a decade $\mathrm{ago}^{10-19}$ and now accounts for $31 \%$ to $53 \%$ of infections. ${ }^{20}$ The NAP1 strain is associated with significant patient morbidity and mortality ${ }^{5}$ and high rates of severe, refractory recurrent $C$. difficile infection. ${ }^{16,18}$ The relative risks of patient-related versus strainrelated factors for recurrence are unknown, as is the comparative efficacy of first-line agents in treating infections associated with the NAP1 strain of $C$. difficile..$^{21,22}$

The treatment of recurrent $C$. difficile infection is often based on empiric selection from relatively few options supported by limited clinical evidence. Accordingly, this paper reviews the recommendations of the Society for Hospital Epidemiology of America and the Infectious Diseases Society of America (SHEA-IDSA; guidelines published in May 2010) and the American College of Gastroenterology (ACOG; guidelines published in February 2013), as well as other references describing treatment strategies for first and second or later recurrence of $C$. difficile infection.

\section{METHODS}

A literature search was conducted in the MEDLINE, PubMed, Embase, and Cochrane databases from inception to 2013 for studies in English that evaluated the treatment of recurrent $C$. difficile infection in adults. All relevant randomized controlled trials (RCTs), observational studies, case series, and case reports were identified using the MeSH (Medical Subject Heading) search terms "Clostridium difficile", "recurrent" or "relapse", and "treatment". Reference lists from retrieved articles and clinical guidelines were also searched for relevant literature. Two reviewers (C.L. and S.Z.) assessed abstracts, full articles, and reference lists from retrieved articles. The reviewers worked collaboratively to determine the relevance of each article to the topic of interest (treatment of recurrent $C$. difficile infection).

\section{RESULTS}

The literature search yielded 24 studies with information about treating recurrent $C$. difficile infection.

\section{Treatment of First Recurrence}

A repeat course of oral metronidazole or oral vancomycin, or a switch from oral metronidazole to oral vancomycin, has been the mainstay treatment for a first recurrence of $C$. difficile

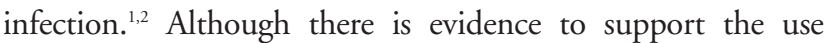
of metronidazole or vancomycin for the initial episode of $C$. difficile infection, there is limited evidence to support the repeat use of either agent in the setting of recurrent infection. The SHEA-IDSA and ACOG guidelines both recommend repeating a 10 - to 14-day course of oral metronidazole $(500 \mathrm{mg}$ every $8 \mathrm{~h}$ ) or vancomycin (125 mg every $6 \mathrm{~h}$ ). ${ }^{1,2}$ Vancomycin is the preferred antibiotic for severe recurrent $C$. difficile infection (Table 1). ${ }^{1,223}$ Failure to respond to metronidazole therapy within 5 to 7 days should prompt consideration of a change in therapy to vancomycin. ${ }^{2,11}$ Both guidelines acknowledge the lack of high-quality evidence to support these recommendations.

The use of either metronidazole or vancomycin for treatment of an initial episode has not been found to influence the likelihood of subsequent recurrence. ${ }^{21,24}$ One early prospective trial found that metronidazole was noninferior to vancomycin, with cure rates exceeding $90 \%$ after treatment of the initial $C$. difficile infection. ${ }^{25}$ However, more recent data, including results for patients with NAP1 infection, have indicated treatment failure rates up to $50 \%$ with metronidazole. ${ }^{11,13,21-23}$ In one prospective observational study of 52 patients with $C$. difficile infection, with $60 \%$ of cases associated with the NAP1 strain, those treated with vancomycin were more likely to have undetectable levels of $C$. difficile toxin (adjusted hazard ratio [HR] $3.99,95 \%$ confidence interval [CI] $1.41-11.3 ; p=0.09)$ and resolution of diarrhea (adjusted HR 4.17, 95\% CI 1.53-11.4; $p=0.05$ ) during the first 5 days of therapy than those who received metronidazole. ${ }^{22}$ Furthermore, therapy was changed because of persistent symptoms in 29\% (10/34) of patients treated with metronidazole but none of the 18 treated with vancomycin. The effect of the NAP1 strain on recurrence was investigated in a retrospective cohort study of 1616 patients with $C$. difficile infection. ${ }^{20}$ The 60-day probability of recurrence in the pre-epidemic period, from 1991 to 2002, was $19.6 \%(108 / 551)$ and $20.3 \%(13 / 64)$ in those treated with metronidazole and vancomycin, respectively. In the postepidemic period, from 2003 to 2004, the recurrence rates were 
Table 1. Criteria for Severe Clostridium difficile Infection

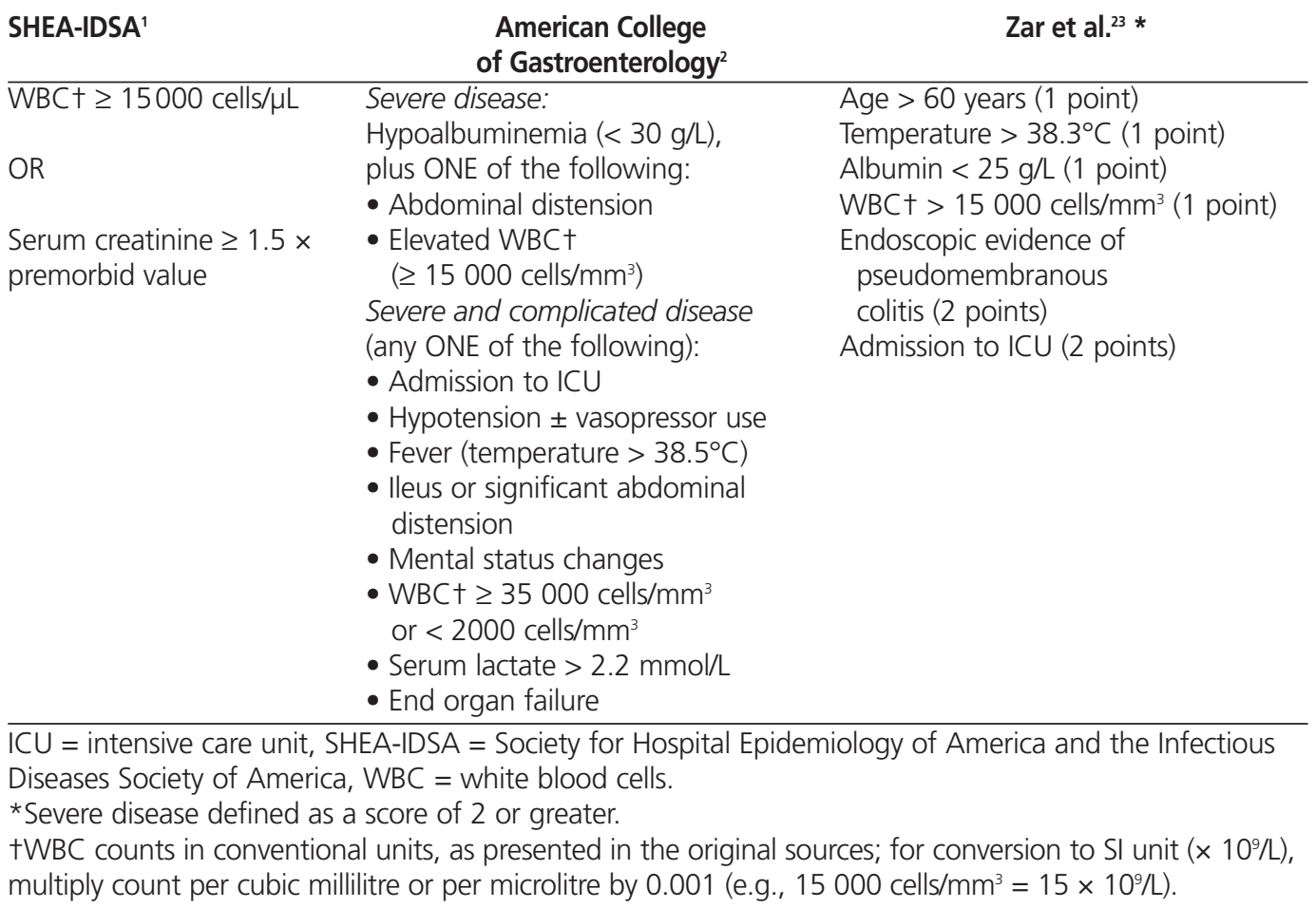

44.6\% (157/352) with metronidazole and 38.7\% (29/75) with vancomycin. However, the statistical significance of these findings was not determined, and the authors noted that the higher risk of recurrence during the 2003-2004 period may have resulted from re-infections rather than relapses. Overall, these findings suggest a possible association between the use of vancomycin and lower rates of subsequent recurrence in the setting of NAP1 infections.

No studies evaluating treatment alternatives in the setting of severe recurrent $C$. difficile infection were found. However, patients with a severe first recurrence are to be treated similarly to those with an initial episode of severe $C$. difficile infection. ${ }^{1,2}$ As such, there are some limitations worth noting in the evidence related to treatment of an initial episode of severe infection. For instance, the use of vancomycin for initial episodes of "severe" $C$. difficile infection was supported by an RCT with 150 patients stratified as having mild or severe disease. ${ }^{23}$ Those with severe disease experienced a higher rate of cure (defined as resolution of diarrhea and negative results on testing for $C$. difficile toxin) with vancomycin (125 mg liquid 4 times daily; cure rate $97 \%$ [30/31]) than with metronidazole (250 mg tablet 4 times daily; cure rate 76\% [29/38]) ( $p=0.02$ ), after 10 days of treatment. Among those with mild disease, no significant difference was observed between vancomycin and metronidazole (98\% [39/40] versus 90\% [37/41]; $p=0.36$ ), and the authors concluded that vancomycin may be preferred for more severe infection. However, the severity score and criteria for "severe" disease were relatively comprehensive (Table
1) including, for example, all patients over 60 years of age with fever or leukocytosis. The severity score and its ability to predict severe clinical infection require prospective validation. In addition, the total daily dose of metronidazole used in this study (1000 mg per day) was lower than that recommended by clinical guidelines (1500 mg per day). ${ }^{1,2}$

Although there were no studies specifically examining patients with severe recurrent $C$. difficile infection or patients with intolerance to oral medication (e.g., those with impaired gastrointestinal absorption or ileus requiring alternate routes of administration), it is useful to examine the interventions that have been used in this setting. Application of retention enemas containing $500 \mathrm{mg}$ vancomycin in $500 \mathrm{~mL}$ normal saline ( $0.9 \%$ sodium chloride) every $6 \mathrm{~h}$ is recommended ${ }^{2}$ on the basis of a case series of 9 patients with $C$. difficile infection (4 of whom had a history of infection 6 weeks before admission). ${ }^{26}$ A volume of at least $500 \mathrm{~mL}$ (more than that previously recommended by the SHEA-IDSA guidelines ${ }^{1}$ ) is thought to improve delivery to the ascending and transverse colon. ${ }^{2}$ However, since rectal administration may not deliver sufficient concentrations of vancomycin to the ascending and transverse colon, concurrent treatment with parenteral metronidazole is recommended. ${ }^{1}$ Because of limited transport across the intestinal membranes, parenteral vancomycin is not used. Notably, the use of parenteral metronidazole as standard treatment for severe infection in those who cannot tolerate oral therapy is also based on limited studies. The relationship between inflammation and drug transport across intestinal 
membranes was examined in a case series of 9 patients with documented $C$. difficile diarrhea; this study showed that fecal metronidazole concentrations decreased as the diarrheal symptoms improved. ${ }^{27}$ No significant difference was found between oral and parenteral routes of administration. In a more recent observational study, Wenisch and other ${ }^{28}$ found that parenteral metronidazole was inferior to oral metronidazole or vancomycin, with 30-day all-cause mortality rates of $38 \%$ (16/42), 7\% (9/121), and 10\% (4/42), respectively. The authors suggested that concentrations of metronidazole in the colon might be lower with parenteral administration. A few possible explanations for this finding include inadequate transit of metronidazole in the absence of mucosal inflammation during mild disease or occurrence of higher colon concentrations with oral metronidazole through metabolic auto-inhibition or enterohepatic recirculation in the intestine..$^{29,30}$ Limitations of the study included enrolment of patients with mild disease, defined as those with fewer than 4 stools per day and no signs of severe colitis. Furthermore, the mortality rate among those receiving parenteral metronidazole was considerably higher than that reported for mild disease. ${ }^{28}$ Although the authors ensured similar baseline age and comorbidities between the groups, selection bias and the influence of unknown confounders on the primary outcome of all-cause mortality cannot be ruled out. The observations, however, draw attention to the relative lack of study of the pharmacokinetics and efficacy of parenteral metronidazole for the treatment of severe C. difficile infection.

\section{Treatment of Second or Later Recurrence}

The treatment options for patients who experience second or later recurrences of $C$. difficile infection are limited. Repeat courses of metronidazole are discouraged because of the risk of neurotoxicity associated with prolonged exposure to this drug. ${ }^{31}$ For example, peripheral neuropathy has been associated with metronidazole use for periods of weeks to months. ${ }^{31}$ Cerebellar dysfunction, altered mental status, and seizures were also described in 64 patients exposed to metronidazole at a mean cumulative dose of $93.4 \mathrm{~g}$ (range $250 \mathrm{mg}$ to $1095 \mathrm{~g}$ ) for a median duration of 54 days. ${ }^{31}$ Therefore, oral vancomycin may be preferred for patients with a second or later recurrence of $C$. difficile infection or predisposing neurologic conditions. A standard 10- to 14-day course of vancomycin (125 mg every $6 \mathrm{~h}$ ) may be used for those with failure of standard metronidazole treatment during the initial episode and first recurrence of $C$. difficile infection. ${ }^{1,2}$

Although the SHEA-IDSA and ACOG guidelines proposed pulsed or tapered vancomycin regimens for those with multiple recurrences of $C$. difficile infection, ${ }^{1,2}$ this approach is largely theoretical. One example of such therapy is the standard 10- to 14-day course of vancomycin $125 \mathrm{mg}$ orally 4 times daily followed by $125 \mathrm{mg}$ twice daily for 1 week, $125 \mathrm{mg}$ once daily for 1 week, and then $125 \mathrm{mg}$ daily pulsed every 2 or 3 days for 2 to 8 weeks. ${ }^{1}$ Pulsed or tapered regimens are thought to be beneficial in suppressing formation of $C$. difficile spores and restoring normal gut flora. It is important to note that there are limited data to support the guideline's claim that "A substantial proportion of patients with a second recurrence will be cured with a tapering and/or pulsed regimen of oral vancomycin".

McFarland and other ${ }^{32}$ conducted a secondary analysis of 2 RCTs comparing Saccharomyces boulardii with placebo as adjunct therapy to various regimens of oral vancomycin or metronidazole. For their analysis, they selected 163 patients from the placebo arms of the 2 trials; these patients had recurrent $C$. difficile infection and an average of 3.2 episodes (range 1 to 14). A fixed vancomycin dose (1000 $\mathrm{mg}$ per day) was used as the comparator for 4 other vancomycin regimens (<1000 mg per day, $\geq 2000 \mathrm{mg}$ per day, tapered, or pulsed), 3 metronidazole regimens ( $\leq 1000 \mathrm{mg}$ per day, $1500 \mathrm{mg}$ per day, or $2000 \mathrm{mg}$ per day), and a miscellaneous group of regimens involving vancomycin plus rifampin or vancomycin plus metronidazole. Treatment durations ranged from 1 to 2 weeks for the fixed dose, from 19 to 25 days for the tapered dose, and from 9 to 20 days for the pulsed regimens. The main observation was a lower recurrence rate, relative to the fixed vancomycin dose $(10 / 14$ [71\%]) with the tapered regimen (9/29 [31\%]; $p=0.01)$ and the pulsed regimen (1/7 [14\%]; $p=0.02$ ). Of note was the exceptionally high recurrence rate for the primary comparator (i.e., fixed vancomycin dose). Other significant limitations included the nonrandomized study design, variable treatment regimens, small sample sizes, and apparent use of multiple comparisons among regimens without appropriate statistical corrections..$^{33}$ The influence of important factors such as duration of therapy were not adequately considered, even though the tapered vancomycin regimens were significantly longer than the fixed-dose regimens (mean of 21.5 days versus 7 to 14 days). At best, the study by McFarland and others ${ }^{32}$ described tapered and pulsed vancomycin regimens in a small number of patients but provided limited evidence as to the effectiveness of these regimens in the treatment of recurrent $C$. difficile infection.

\section{Fidaxomicin}

Fidaxomicin (Dificid) received notice of compliance for the treatment of $C$. difficile infection from Health Canada in June 2012. ${ }^{34}$ It is a narrow-spectrum macrocyclic antibiotic that exhibits minimal systemic absorption. It is bactericidal and demonstrates prolonged post-antibiotic effects against $C$. difficile. ${ }^{35}$ Fidaxomicin has been shown to be safe and effective for the first episode of $C$. difficile infection ${ }^{36,37}$; however, there is limited evidence for recurrent infection. 
Fidaxomicin was compared with vancomycin in 2 RCTs involving a total of more than 500 patients with mild to moderate C. difficile infection. ${ }^{36,37}$ Approximately $16 \%$ of the patients had had a previous episode of infection. Both trials found that 10 days of oral fidaxomicin (200 mg twice daily) was noninferior to 10 days of oral vancomycin $(125 \mathrm{mg} 4$ times daily) in terms of clinical cure. In the first trial, by Louie and others, ${ }^{36} 88.2 \%(253 / 287)$ of patients in the fidaxomicin group and $85.8 \%(265 / 309)$ of those in the vancomycin group experienced clinical cure (one-sided $97.5 \%$ confidence limit $-3.1 \%) .{ }^{36}$ In the second trial, Cornely and other ${ }^{37}$ reported a clinical cure rate of $87.7 \%(221 / 252)$ for the fidaxomicin group and $86.8 \%$ (223/257) for the vancomycin group (one-sided $97.5 \%$ confidence limit $-4.9 \%$ ). Fidaxomicin was also associated with a lower recurrence rate within 28 days of clinical cure relative to vancomycin $(15.0 \%$ versus $25.0 \%$, respectively; $p=0.005$; relative risk $[\mathrm{RR}] 0.39) .{ }^{36}$ Intestinal effects, such as nausea and abdominal discomfort, were the most commonly reported adverse effects in patients receiving fidaxomicin..$^{36-38}$

Cornely and others ${ }^{38}$ conducted a retrospective subgroup analysis of the 128 patients with recurrent $C$. difficile infection in the aforementioned studies. In these patients, initial response, defined as clinical cure after 8 or more days of therapy, was similar for fidaxomicin and vancomycin. Recurrence within 28 days, however, was significantly less likely among patients who received fidaxomicin (20\% [13/66] versus $35 \%$ [22/62], $p=0.045$ ). Although this was a retrospective subgroup analysis with small sample size, these findings suggest that fidaxomicin may have a role in treating recurrent $C$. difficile infection. Of note, fidaxomicin has not been compared with metronidazole, and additional prospective studies are also needed in patients with severe $C$. difficile infection, as well as those with multiple episodes of recurrent infection.

Drug cost is an important consideration in defining the role of fidaxomicin in the treatment of $C$. difficile infection, including recurrent infection. The cost of this drug is approximately $\$ 2200$ for 10 days of treatment, ${ }^{39}$ whereas the corresponding costs are $\$ 550$ for vancomycin and $\$ 25$ for metronidazole..$^{40}$ The Canadian Drug Expert Committee of the Canadian Agency for Drugs and Technologies in Health has recommended that fidaxomicin not be listed on formulary at this price. ${ }^{41}$ In addition, one economic analysis concluded that the use of fidaxomicin is not a cost-effective option for first-line treatment of $C$. difficile infection. ${ }^{42}$ According to the authors of this study, the cost of a course of treatment with fidaxomicin would have to be no more than $\$ 150$ to be considered cost-effective. ${ }^{42}$ Interestingly, selective treatment of patients with the non-NAP1 strain of $C$. difficile is more cost-effective; however, the incremental cost-effectiveness ratio was estimated to be greater than $\$ 43.7$ million per quality-adjusted life-year in the setting of screened patients. ${ }^{42}$

\section{Other Alternatives}

Other alternatives for treating recurrent $C$. difficile infection that have been investigated in clinical trials include anion exchange resins, other antibiotics (such as rifaximin), probiotics, and fecal microbiota transplant. The clinical guidelines do not support the use of anion exchange resins or other antibiotics in the management of recurrent infection. ${ }^{1,2}$ Anion exchange resins, such as cholestyramine, are thought to bind toxins produced by $C$. difficile without altering the bowel flora. ${ }^{1}$ However, they have also been found to bind oral vancomycin, which results in reduced efficacy of the drug, ${ }^{1}$ and concurrent use of resins with vancomycin should therefore be avoided. There have been no studies in which binding of anion exchange resins to metronidazole was observed; however, this theoretical concern should not be ruled out. Rifamixin is a nonabsorbable rifamycin antibiotic that is not available in Canada but has been used in the United States for recurrent $C$. difficile infection. ${ }^{1,2}$ In one pilot study of 68 patients with $C$. difficile infection, administration of rifaximin following standard antibiotic therapy (with 56 patients [82\%] receiving metronidazole and 12 [18\%] receiving oral vancomycin for 10 to 14 days; standard doses not specified) resulted in a reduction in recurrent $C$. difficile infection relative to placebo; however, this finding was not statistically significant $(15 \%[5 / 33]$ versus $31 \%$ [11/35]; $p=0.11) .{ }^{43}$ In this study, the mean age was 61 years, 34 (50\%) of the patients were female, and 13 (19\%) had had a previous episode of $C$. difficile infection. ${ }^{43}$

There is insufficient evidence to recommend probiotic therapy as an adjunct to conventional treatment for recurrent C. difficile infection. ${ }^{1,2}$ One Cochrane review of 4 small randomized, prospective studies found no overall benefit of probiotics in conjunction with conventional treatment for initial or recurrent episodes of $C$. difficile infection. ${ }^{44}$ In one of the studies included in the Cochrane review, there was a significant reduction in recurrent $C$. difficile diarrhea with $S$. boulardii in addition to conventional therapy relative to placebo (RR 0.59 , 95\% CI 0.35-0.98). ${ }^{45}$ In another study included in the Cochrane review, there was a significant reduction in recurrent C. difficile infection with $S$. boulardii (relative to placebo) only when used in combination with high-dose vancomycin ( $2 \mathrm{~g}$ per day) (RR 0.33, 95\% CI 0.10-1.06). ${ }^{46}$ However, there was no significant difference in recurrent $C$. difficile infection when $S$. boulardii was used in combination with low-dose vancomycin (500 mg per day) or metronidazole. No statistically significant benefit was found with Lactobacillus plantarum or Lactobacillus rhamnosis GG in the remaining 2 studies. ${ }^{47,48}$

Despite the limitations of probiotics in treating $C$. difficile infection, there is some evidence to support their value in 
preventing such infection. ${ }^{49,50}$ In one meta-analysis of 22 trials ( $n=3818$ ), the incidence of $C$. difficile-associated diarrhea was approximately $66 \%$ lower among patients receiving probiotics than among those receiving placebo or no treatment (pooled RR $0.34,95 \%$ CI $\left.0.24-0.49 ; I^{2}=0 \%\right){ }^{49}$ These agents are not recommended for immunocompromised, critically ill, or elderly patients or for patients with inflamed or leaky gastrointestinal mucosa, as there have been cases of invasive infection in such patients. ${ }^{2}$ For most probiotics, there are also some concerns about quality control and inconsistency of the quantity of live organisms. ${ }^{2}$ The clinical guidelines acknowledge the lack of convincing evidence for the use of adjunctive probiotics to reduce recurrent $C$. difficile infection. ${ }^{1,2}$

Fecal microbiota transplant (FMT) may have a role for patients who have had 3 or more recurrent infections, ${ }^{2,51}$ and the ACOG guidelines recommend consideration of this approach after a third recurrence of $C$. difficile infection following a pulsed vancomycin regimen. ${ }^{2}$ FMT involves transplanting stool from a healthy donor into the patient with recurrent $C$. difficile infection. ${ }^{2}$ Patients with recurrent infection may have an imbalance in the amount of healthy colonic flora, and introducing normal fecal bacteria from a healthy donor may be restorative. Various methods have been used for FMT, including retention enemas, nasoduodenal tube, and colonoscopy. ${ }^{2.51}$ Approximately 325 cases of FMT have been reported in the literature. ${ }^{2}$ Kassam and others ${ }^{51}$ performed a systematic review of 11 studies (with no RCTs identified) and found that 245 of 273 patients with $C$. difficile infection experienced clinical resolution of diarrhea with FMT treatment (weighted pooled resolution rate $89.1 \%, 95 \%$ CI 84\%-93\%), with no statistically significant heterogeneity among the studies $\left(I^{2}=33.7 \%\right)$. In a retrospective case series of 70 patients with recurrent $C$. difficile infection, symptom resolution was reported at 12 weeks for all patients without the NAP1 strain and for $89 \%(32 / 36)$ of those with the NAP1 strain. ${ }^{52}$ The US Food and Drug Administration recently categorized FMT as a "drug and biologic product", and hence an Investigational New Drug application is required for its use. ${ }^{53}$

One open-label RCT involving adults with recurrent $C$. difficile compared a standard 14-day course of vancomycin (500 mg 4 times daily) with (1) a 14-day course of the same drug therapy with bowel lavage on day 4 or 5 and (2) a 5-day course of drug therapy with bowel lavage on the last day followed by FMT via nasoduodenal infusion the next day. ${ }^{54}$ Thirteen $(81 \%)$ of the 16 patients in the FMT group, 4 (31\%) of the 13 patients in the vancomycin-only group, and $3(23 \%)$ of the 13 patients in the vancomycin plus bowel lavage group experienced resolution of $C$. difficile-associated diarrhea without recurrence after 10 weeks ( $p<0.001$; rate ratio 3.05 [99.9\% CI 1.08-290.05] between the FMT and vancomycin-only group and 4.05 [99.9\% CI 1.21-290.12] between the FMT and vancomycin with bowel lavage group) ${ }^{54}$ Mild diarrhea and abdominal cramping were reported more often in the infusion group; however, no significant difference was observed relative to the other treatment groups. A major limitation of concern was early termination because of lower-than-expected cure rates in the control group (patients receiving vancomycin). Given the small sample size, it is difficult to determine the effect of baseline differences on the results of this study. Long-term data for this intervention are limited, and the potential for transmission of infectious organisms is of concern. ${ }^{2}$

\section{CONCLUSION}

Recurrent C. difficile infection remains a challenging illness for which an optimal treatment approach has not been well established. Recommendations presented in formal guidelines $^{1,2}$ are largely supported by expert opinion and small case series.

The literature review reported here indicates that a repeat course of metronidazole or vancomycin is considered appropriate for the treatment of mild to moderate first recurrence of $C$. difficile infection. Although oral vancomycin is recommended for more severe $C$. difficile infection, a validated severity score has yet to be established, and comparative data with recommended metronidazole doses are not available. Parenteral metronidazole is a suggested addition to oral vancomycin for critically ill patients with ileus. However, in one observational study, the mortality rate was higher with parenteral metronidazole than with oral alternatives in patients with mild to moderate disease. ${ }^{1,31}$ The clinical impact of parenteral metronidazole in severe disease has not been studied. For the treatment of second or later recurrence, a tapered or pulsed regimen is recommended, but the best available evidence in support of this practice is limited. A longer (3-week) treatment course of oral vancomycin may have some benefit for patients with a second or later recurrence; however, further studies are needed to support this practice. Fidaxomicin has shown promise in patients with mild to moderate $C$. difficile infection, and new data are emerging to support its efficacy in patients with recurrent $C$. difficile infection. FMT may have a role in patients who have experienced 3 or more recurrences; however, RCTs and long-term efficacy and safety data are still needed.

There has been recent concern regarding the toxin hyperproducing NAP1 strain of $C$. difficile; however, in the majority of studies examining patients with recurrent infection, this strain has not been implicated.

Only a few studies have exclusively examined patients with second or later recurrence. More research in this area is needed given the limited options available at this stage.

This literature review has identified substantial limitations in currently recommended interventions for the treatment of recurrent $C$. difficile infection. It also provides insight into 
the available evidence for determining the appropriateness of therapy for patients presenting with recurrent infection of this type.

\section{References}

1. Cohen SH, Gerding DN, Johnson S, Kelly CP, Loo VG, McDonald LC, et al. Clinical practice guidelines for Clostridium difficile infection in adults: 2010 update by the Society for Healthcare Epidemiology of America (SHEA) and the Infectious Diseases Society of America (IDSA). Infect Control Hosp Epidemiol. 2010;31(5):431-55.

2. Surawicz CM, Brandt LJ, Binion DG, Ananthakrishnan AN, Curry SR, Gilligan PH, et al. Guidelines for diagnosis, treatment, and prevention of Clostridium difficile infections. Am J Gastroenterol. 2013;108(4):478-98.

3. Aslam S, Hamill RJ, Musher DM. Treatment of Clostridium difficile-associated disease: old therapies and new strategies. Lancet Infect Dis. 2005;5(9):549-57.

4. Ghantoji SS, Sail K, Lairson DR, DuPont HL, Garey KW. Economic healthcare costs of Clostridium difficile infection: a systematic review. J Hosp Infect. 2010;74(4):309-18.

5. Miller MA, Hyland M, Ofner-Agostini M, Gourdeau M, Ishak M; Canadian Hospital Epidemiology Committee. Morbidity, morality, and healthcare burden of nosocomial Clostridium difficile-associated diarrhea in Canadian hospitals. Infect Control Hosp Epidemiol. 2002;23(3):137-40.

6. Simor A, Bradley SF, Strausbaugh LJ, Crossley K, Nicolle LE; SHEA LongTerm-Care Committee. Clostridium difficile in long-term-care facilities for the elderly. Infect Control Hosp Epidemiol. 2002;23(11):696-703.

7. Dubberke E. Clostridium difficile infection: the scope of the problem. J Hosp Med. 2012;7(Suppl 3):S1-4.

8. Johnson S, Clabots CR, Linn FV, Olson MM, Peterson LR, Gerding DN. Nosocomial Clostridium difficile colonisation and disease. Lancet. 1990; 336(8707):97-100.

9. Kasper AM, Nyazee HA, Yokoe DS, Mayer J, Mangino JE, Khan YM, et al.; Centers for Disease Control and Prevention Epicenters Program. A multicenter study of Clostirium difficile infection-related colectomy, 2000-2006. Infect Control Hosp Epidemiol. 2012;33(5):470-6.

10. Kyne L, Warny M, Qamar A, Kelly CP. Association between antibody response to toxin $\mathrm{A}$ and protection against recurrent Clostridium difficile diarrhoea. Lancet. 2001;357(9251):189-93.

11. Musher DM, Aslam S, Logan N, Nallacheru S, Bhaila I, Borchert F, et al. Relatively poor outcome after treatment of Clostridium difficile colitis with metronidazole. Clin Infect Dis. 2005;40(11):1586-90.

12. Bartlett JG. Clinical practice. Antibiotic-associated diarrhea. $N$ Engl J Med. 2002;346(5):334-9.

13. Pepin J. Vancomycin for the treatment of Clostridium difficile infection: For whom is this expensive bullet really magic? Clin Infect Dis. 2008;46(10):1493-8.

14. MacCannell DR, Louie TJ, Gregson DB, Laverdiere M, Labbe AC, Laing F, et al. Molecular analysis of Clostridium difficile PCR ribotype 027 isolates from eastern and western Canada. J Clin Microbiol. 2006;44(6):2147-52.

15. Pépin J, Valiquette L, Alary ME, Villemure P, Pelletier A, Forget K, et al. Clostridium difficile-associated diarrhea in a region of Quebec from 1991 to 2003: a changing pattern of disease severity. CMAJ. 2004;171(5):466-72.

16. Loo VG, Poirier L, Miller MA, Oughton M, Libman MD, Michaud S, et al. A predominantly clonal multi-institutional outbreak of Clostridium difficileassociated diarrhea with high morbidity and mortality. $N$ Engl $J$ Med. 2005;353(23):2442-9.

17. Pépin J, Valiquette L, Cossette B. Mortality attributable to nosocomial Clostridium difficile-associated disease during an epidemic caused by a hypervirulent strain in Quebec. CMAJ. 2005;173(9):1037-41.

18. Pépin J, Saheb N, Coulombe MA, Alary ME, Corriveau MP, Authier S, et al. Emergence of fluorquinolones as the predominant risk factor for Clostridium difficile-associated diarrhea: a cohort study during an epidemic in Quebec. Clin Infect Dis. 2005;41(9):1254-60.

19. Miller M, Gravel D, Mulvey M, Taylor G, Boyd D, Simor A, et al. Health care-associated Clostiridium difficile infection in Canada: patient age and infecting strain type are highly predictive of severe outcome and mortality. Clin Infect Dis. 2010;50(2):194-201.
20. Pépin J, Valiquette L, Gagnon S, Routhier S, Brazeau I. Outcomes of Clostridium difficile-associated disease treated with metronidazole or vancomycin before and after the emergence of NAP1/027. Am J Gastroenterol. 2007;102(12):2781-8.

21. Belmares J, Gerding DN, Parada JP, Miskevics S, Weaver F, Johnson S. Outcome of metronidazole therapy for Clostridium difficile disease and correlation with a scoring system. J Infect. 2007;55(6):495-501.

22. Al-Nassir WN, Sethi AK, Nerandzic MM, Bobulsky GS, Jump RL, Donskey CJ. Comparison of clinical and microbiological response to treatment of Clostridium difficile-associated disease with metronidazole and vancomycin. Clin Infect Dis. 2008;47(1):56-62.

23. Zar FA, Bakkanagari SR, Moorthi KMLST, Davis MB. A comparison of vancomycin and metronidazole for the treatment of Clostridium difficile-associated diarrhea, stratified by disease severity. Clin Infect Dis. 2007;45(3):302-7.

24. Fernandez A, Anand G, Riedenberg F. Factors associated with failure of metronidazole in Clostridium difficile-associated disease. J Clin Gastroenterol. 2004;38(5):414-8.

25. Teasley DG, Gerding DN, Olson MM, Peterson LR, Gebhard RL, Schwartz MJ, et al. Prospective randomised trial of metronidazole versus vancomycin for Clostridium difficile-associated diarrhoea and colitis. Lancet. 1983;2(8358): 1043-6.

26. Apisarnthanarak A, Razavi B, Mundy LM. Adjunctive intracolonic vancomycin for severe Clostridium difficile colitis: case series and review of the literature. Clin Infect Dis. 2002;35(6):690-6.

27. Bolton RP, Culshaw MA. Faecal metronidazole concentrations during oral and intravenous therapy for antibiotic associated colitis due to Clostridium difficile. Gut. 1986;27(10):1169-72.

28. Wenisch JM, Schmid D, Kuo HW, Allerberger F, Michl V, Tesik P, et al. Prospective observational study comparing three different treatment regimes in patients with Clostridium difficile infection. Antimicrob Agents Chemother. 2012;56(4):1974-8.

29. Mattila J, Männistö PT, Mäntylä R, Nykänen S, Lamminsivu U. Comparative pharmacokinetics of metronidazole and tinidazole as influenced by administration route. Antimicrob Agents Chemother. 1983;23(5):721-5.

30. Thiercelin JF, Diquet B, Levesque C, Ghesquiére F, Simon P, Viars P. Metronidazole kinetics and bioavailability in patients undergoing ganstrointestinal surgery. Clin Pharmacol Ther. 1984;35(4):510-9.

31. Kuriyama A, Jackson JL, Doi A, Kamiya T. Metronidazole-induced central nervous system toxicity: a systematic review. Clin Neuropharmacol. 2011; 34(6):241-7.

32. McFarland LV, Elmer GW, Surawicz CM. Breaking the cycle: treatment strategies for 163 cases of recurrent Clostridium difficile disease. Am J Gastroenterol. 2002;97(7):1769-75.

33. Gordi T, Khamis H. Simple solution to a common statistical problem: interpreting multiple tests. Clin Ther. 2004;26(5):780-6.

34. Summary basis of decision (SBD) for DIFICID ${ }^{\mathrm{TM}}$. Control number 151086. Ottawa (ON): Health Canada; 2012 Oct 30 [cited 2013 Nov 13]. Available from: www.hc-sc.gc.ca/dhp-mps/prodpharma/sbd-smd/drug-med/sbd_smd_ 2012_dificid_151086-eng.php

35. DIFICID® (fidaxomicin) [product monograph]. Toronto (ON): Optimer Pharmaceuticals Canada Inc; revised 2012 Jun 4.

36. Louie TJ, Miller MA, Mullane KM, Weiss K, Lentnek A, Golan Y, et al.; OPT-80-003 Clinical Study Group. Fidaxomicin versus vancomycin for Clostridium difficile infection. N Engl J Med. 2011;364(5):422-31.

37. Cornely OA, Crook DW, Esposito R, Poirier A, Somero MS, Weiss K, et al.; OPT-80-004 Clinical Study Group. Fidaxomicin versus vancomycin for infection with Clostridium difficile in Europe, Canada, and the USA: a double-blind, non-inferiority, randomised controlled trial. Lancet Infect Dis. 2012;12(4):281-9.

38. Cornely OA, Miller MA, Louie TJ, Crook DW, Gorbach SL. Treatment of first recurrence of Clostridium difficile infection: fidaxomicin versus vancomycin. Clin Infect Dis. 2012;55 Suppl 2:S154-61.

39. New C. diff drug approved. The Canadian Press; 2012 Jul 5 [cited 2012 Aug 12]. Available from: www.thespec.com/print/article/755566

40. Ontario drug benefit formulary/comparative drug index. Toronto (ON): Ministry of Health and Long-Term Care; updated 2012 Aug 27 [cited 2012 
Aug 31]. Available from: https://www.healthinfo.moh.gov.on.ca/formulary/ index.jsp

41. Common drug review - notice of CDEC final recommendation: fidaxomicin. Ottawa (ON): Canadian Agency for Drugs and Technologies in Health; 2012 Dec 19.

42. Bartsch SM, Umscheid CA, Fishman N, Lee BY. Is fidaxomycin worth the cost? An economic analysis. Clin Infect Dis. 2013;57(4):555-61.

43. Garey KW, Ghantoji SS, Shah DN, Habib M, Arora V, Jiang ZD, et al. A randomized, double-blind, placebo-controlled pilot study to assess the ability of rifaximin to prevent recurrent diarrhoea in patients with Clostridium difficile infection. J Antimicrob Chemother. 2011;66(12):2850-5.

44. Pillai A, Nelson RL. Probiotics for treatment of Clostridium difficile-associated colitis in adults. Cochrane Database Syst Rev. 2008;(1):CD004611.

45. McFarland LV, Surawicz CM, Greenberg RN, Fekety R, Elmer GW, Moyer $\mathrm{KA}$, et al. A randomized placebo-controlled trial of Saccharomyces boulardii in combination with standard antibiotics for Clostridium difficile disease. JAMA. 1994;271(24):1913-8.

46. Surawicz CM, McFarland LV, Greenberg RN, Rubin M, Fekety R, Mulligan $\mathrm{ME}$, et al. The search for a better treatment for recurrent Clostridium difficile disease: use of high-dose vancomycin combine with Saccharomyces boulardii. Clin Infect Dis. 2000;31(4):1012-7.

47. Lawrence SJ, Korzenik JR, Mundy LM. Probiotics for recurrent Clostridium difficile disease. J Med Microbiol. 2005;54(Pt 9):905-6.

48. Wullt M, Hagslätt ML, Odenholt I. Lactobacillus plantarum 299v for the treatment of recurrent Clostridium difficile associated diarrhoea: a doubleblind, placebo-controlled trial. Scand J Infect Dis. 2003;35(6-7):365-7.

49. Johnston BC, Ma SS, Goldenberg JZ, Thorlund K, Vandvik PO, Loeb M, et al. Probiotics for the prevention of Clostridium difficile-associated diarrhea: a systematic review and meta-analysis. Ann Intern Med. 2012;157(12):878-88.

50. Friedman G. The role of probiotics in the prevention and treatment of antibiotic-associated diarrhea and Clostirdium difficile colitis. Gastroenterol Clin North Am. 2012;41(4):763-79.
51. Kassam Z, Lee CH, Yuan Y, Hunt RH. Fecal microbiota transplantation for Clostridium difficile infection: systematic review and meta-analysis. Am J Gastroenterol. 2013;108(4):500-8.

52. Mattila E, Uusitalo-Seppälä R, Wuorela M, Lehtola L, Nurmi H, Ristikankare $\mathrm{M}$, et al. Fecal transplantation, through colonoscopy, is effective therapy for recurrent Clostridium difficile infection. Gastroenterology. 2012;142(3):490-6.

53. Midthun K. Letter to C. Richard Boland, American Gastroenterological Association. Rockville (MD): Department of Health and Human Services, Food and Drug Administration, Public Health Service; 2013 Apr 25 [cited 2013 Jun 27]. Available from: http://highroadsolution.com/file_upload_2/files/ fda+response+letter+to+fmt+inquiry.pdf

54. Van Nood E, Vrieze A, Nieuwdorp M, Fuentes S, Zoetendal EG, de Vos WM, et al. Duodenal infusion of donor feces for recurrent Clostridium difficile. $N$ Engl J Med. 2013;368(5):407-15.

Christine Leong, BScPhm, PharmD, is with the Faculty of Pharmacy, Apotex Centre, University of Manitoba, Winnipeg, Manitoba.

Sheryl Zelenitsky, BScPhm, PharmD, is with the Faculty of Pharmacy, Apotex Centre, University of Manitoba, Winnipeg, Manitoba.

Competing interests: None declared.

Address correspondence to:

Dr Christine Leong

Faculty of Pharmacy, Apotex Centre

University of Manitoba

750 McDermot Avenue

Winnipeg MB R3E 0T5

e-mail: christine.leong@umanitoba.ca

\section{CISADL 2013}

\section{Order your copy of the 2013 Canadian Investigational \& Special Access Drug List today!}

\section{Please use the CSHP order form found online at CSHP.ca to place your order.}

The CISADL is a compilation of drugs that are currently not marketed in Canada and may have Investigational or Special Access status with Health Canada. This list is not endorsed by Health Canada's Special Access Program. For precise information about the regulatory status of a drug, contact the Special Access Program directly. Entries to the list are contributed to by several Drug Information Centers across Canada and by Canadian drug manufacturers. In cases where non-marketed drugs do not appear on the list, foreign references should be consulted. The content of the list includes generic name and strength/concentration, dosage form, pharmacology/therapeutic use, trade and code name, source (manufacturer/distributor), and comments. Available in English only.

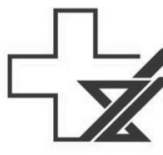
Société canadienne des pharmaciens d'hôpitaux 